Revista

Ibero-Americana

de Estratégıa

GESTÃo ESTRATÉGICA DE PESSOAS NAS ORGANIZAÇÕES PETROQUÍMICAS DE CAMAÇARI - BAHIA: SEUS REFLEXOS NAS ESTRATÉGIAS DE ATRAÇÃO, RETENÇÃO E DESENVOLVIMENTO DE PROFISSIONAIS *

*Pesquisa Financiada pela FAPESP

STRATEGIC MANAGEMENT OF PEOPLE IN ORGANIZATIONS OF

PETROCHEMICAL CAMAÇARI - BAHIA: REFLECTIONS ON ITS STRATEGIES FOR ATTRACTING, RETAINING AND PROFESSIONAL DEVELOPMENT

DIRECCIÓN ESTRATÉGICA DE PERSONAS EN LAS ORGANIZACIONES DEL POLO PETROQUÍMICO DE CAMAÇARI - BAHIA: REFLEXIONES SOBRE SUS ESTRATEGIAS PARA ATRAER, RETENCIÓN Y DESARROLLO PROFESIONAL

Nildes Pitombo Leite

Doutora em Administração pela Faculdade de Economia, Contabilidade e Administração da Universidade de São Paulo - FEA/USP

Professora do Programa de Pós Graduação em Administração da Universidade Nove de Julho PPGA/UNINOVE

E-mail: nildesrpl@uninove.br (Brasil)

Lindolfo Galvão de Albuquerque

Doutor em Administração Universidade de São Paulo - USP

Professor da Universidade de São Paulo - USP

E-mail: Igdalbuq@usp.br (Brasil) 
Gestão Estratégica de Pessoas nas Organizações Petroquímicas de Camaçari - Bahia: Seus Reflexos nas Estratégias de Atração, Retenção e Desenvolvimento de Profissionais

\title{
GESTÃO ESTRATÉGICA DE PESSOAS NAS ORGANIZAÇÕES PETROQUÍMICAS DE CAMAÇARI - BAHIA: SEUS REFLEXOS NAS ESTRATÉGIAS DE ATRAÇÃO, RETENÇÃO E DESENVOLVIMENTO DE PROFISSIONAIS
}

\section{RESUMO}

A investigação, objeto de estudo desta pesquisa, teve por objetivos primordiais identificar e analisar quais as mudanças realizadas na gestão de pessoas pelas organizações petroquímicas, a partir da trajetória de diversificação no complexo industrial de Camaçari, e os seus reflexos nas estratégias de atração, retenção e desenvolvimento de profissionais, tanto em consonância com as justificativas, quanto com a questão formulada. Os sujeitos envolvidos foram diretores, gerentes e/ou coordenadores de RH, tempo mínimo de 10 e máximo de 32 anos, dois entrevistados por organização, totalizando vinte e uma organizações. Tal investigação foi respondida paulatinamente em cada categoria e reforçada na junção de todas elas. Os resultados mostram que as mudanças realizadas em gestão de pessoas nas petroquímicas investigadas não são, necessariamente, computadas a partir da trajetória de diversificação: Pólo Petroquímico / Complexo Industrial de Camaçari. Esses resultados apontam que as fusões estão entre as principais responsáveis. Todavia, há o registro de que essa mudança de contexto foi benéfica, ao favorecer a saída dessas organizações da zona de conforto que se encontravam desde a implantação do Pólo. Consolida-se a premissa de que tal investigação encerra aspecto inovador e contributivo para a área de gestão de pessoas, o setor petroquímico e o país.

Palavras-chave: Estratégias de Atração; Gestão Estratégica de Pessoas; Organizações Petroquímicas; Retenção e Desenvolvimento.

\section{STRATEGIC MANAGEMENT OF PEOPLE IN ORGANIZATIONS OF}

PETROCHEMICAL CAMAÇARI - BAHIA: REFLECTIONS ON ITS STRATEGIES FOR ATTRACTING, RETAINING AND PROFESSIONAL DEVELOPMENT

\begin{abstract}
The investigation object of this research, the primary objectives was to identify and analyze what changes made in people management by the petrochemical organizations, from the trajectory of diversification in the Industrial Complex of Camaçari and their reflections into strategies for attraction, retention and professional development, much in line with the justifications, as with the question asked. The subjects involved were directors, managers and / or coordinators HR, minimum 10 and maximum of 32 years, two respondents per organization, totaling twenty-one organizations. This investigation was answered in each category and gradually increased at the junction of them all. The results show that the changes made in managing people in the petrochemical investigated are not, necessarily, computed from the trajectory of diversification: Petrochemical Pole / Industrial Complex of Camaçari. These results suggest that mergers are among the main responsible. However, there is the record that this change in context was beneficial to these organizations promote the output of the comfort zone that were since deploying Pole. It reinforces the premise that such an investigation ends innovative and contributory aspect for: the area of people management, petrochemical industry and the country.
\end{abstract}

Keywords: Petrochemical Companies; Strategic Management of People; Strategies for Attracting; Retaining and Developing.

Revista Ibero-Americana de Estratégia - RIAE, São Paulo, v. 11, n. 3, p. 61-96, set./dez. 2012. 
Nildes Pitombo Leite \& Lindolfo Galvão de Albuquerque

\section{DIRECCIÓN ESTRATÉGICA DE PERSONAS EN LAS ORGANIZACIONES DEL POLO PETROQUÍMICO DE CAMAÇARI - BAHIA: REFLEXIONES SOBRE SUS ESTRATEGIAS PARA ATRAER, RETENCIÓN Y DESARROLLO PROFESIONAL}

\section{RESUMEN}

El objeto de estudio de esta investigación fue identificar y analizar los principales objetivos que los cambios realizados en la gestión de personas organizaciones petroquímica, de la trayectoria de la diversificación en el complejo industrial de Camaçari, y sus reflexiones sobre estrategias para atraer, retener y el desarrollo del personal, tanto en línea con las justificaciones, en cuanto a la cuestión planteada. Los sujetos participantes fueron directores, gerentes y / o de recursos humanos coordinadores, mínimo de 10 y un máximo de 32 años, dos entrevistados por la organización, por un total de veintiuna organizaciones. Dicha encuesta fue respondida en cada categoría y reforzado gradualmente en la unión de todos ellos. Los resultados muestran que los cambios realizados en la gestión de personal en la industria petroquímica investigado no necesariamente se calcula a partir de la trayectoria de diversificación: Petroquímica / Complejo Industrial de Camaçari. Estos resultados indican que las fusiones están entre los principales culpables. Sin embargo, no hay constancia de que este cambio de contexto es beneficioso para estas organizaciones promueven la salida de la zona de confort que fueron desde el despliegue de Polo. Esto refuerza la premisa de que tales fines la investigación y el aspecto innovador que contribuye a la gestión de personal, la industria petroquímica y del país.

Palabras-clave: Estrategias de Atracción; Gestión Estratégica de Personas; Petroquímica Organizaciones; Retención y Desarrollo. 
Gestão Estratégica de Pessoas nas Organizações Petroquímicas de Camaçari - Bahia: Seus Reflexos nas Estratégias de Atração, Retenção e Desenvolvimento de Profissionais

\section{INTRODUÇÃO}

Em todo o mundo, as alterações sociais, econômicas e políticas têm impactado as relações de trabalho. No passado, essas relações eram mais perenes e duradouras, fazendo com que os trabalhadores, muitas vezes, permanecessem em um mesmo emprego por toda a sua vida laborativa. As novas demandas do mundo do trabalho estão provocando o surgimento de novos valores, novos objetivos e metas, novas políticas e práticas, redefinindo interações entre as pessoas e as organizações.

Nesse contexto de alterações, a gestão estratégica de pessoas nas organizações apresenta-se como um tema recorrente e desafiador para os pesquisadores, diante da crescente descoberta da necessidade de valorização do intangível: o capital humano como fonte de valor e de competitividade organizacional, com base em Ulrich (1997; 1998; 2000); Dessler (2003); Albuquerque (1999); Albuquerque \& Leite (2009); Ulrich \& Ulrich (2011); Ulrich, Allen, Brockbank, Younger \& Nyman (2011). Alinhados a tal descoberta, Martín-Alcázar, Romero-Fernádez \& Sánchez-Gardey, (2008) sugeriram que grande parte da pesquisa em gestão de pessoas se baseia no pressuposto básico da teoria comportamental, tomandose o comportamento dos empregados como elemento-chave das estratégias de gestão de pessoas e como moderador potencial de seus efeitos sobre o desempenho.

Por sua vez, o setor petroquímico tem importância reconhecida como fundamental na economia brasileira e no dia a dia do cidadão e, graças a esse fato, também atrai a atenção de pesquisadores. Com o advento de novas indústrias em um pólo petroquímico, as petroquímicas podem ter se visto na contingência de precisar repensar suas políticas e práticas de gestão de pessoas, a fim de conseguir atrair, reter e desenvolver seus profissionais. Nesse processo, essas organizações podem ter reagido de forma diferenciada em relação a esse desafio, sendo importante para a sociedade o entendimento desse processo, visando o desenvolvimento do mercado de trabalho nesse setor.

Compreende-se que as mudanças no ambiente externo geram mudanças na estratégia organizacional que, por sua vez, geram alterações nas estratégias de atração, retenção e desenvolvimento de profissionais. Atualmente, o desafio encontrado pelas organizações desse setor está requerendo novas estratégias de atração, retenção e desenvolvimento de profissionais. Assim, justifica-se o interesse por esta pesquisa:

Revista Ibero-Americana de Estratégia - RIAE, São Paulo, v. 11, n. 3, p. 61-96, set./dez. 2012. 
- O pólo petroquímico de Camaçari é o primeiro complexo petroquímico planejado do país. Trata-se de um ambiente em processo de transformação. A produção de automóveis pela Ford ajudou a transformá-lo em um complexo industrial, com perspectivas de integração do segmento petroquímico com a indústria de transformação.

Esse complexo industrial é responsável por parte do desenvolvimento da cidade de Camaçari e por $30 \%$ do PIB do Estado da Bahia, desde sua implantação (1978) como unidade de produção petroquímica, até sua transformação no maior complexo industrial integrado do Hemisfério Sul (Cofic - Comitê de Fomento Industrial de Camaçari, 2008). A atração de novos empreendimentos gerou um novo ciclo de expansão, com mais oportunidade de emprego e renda para o Nordeste. Esse complexo é responsável por quinze mil empregos diretos e vinte mil indiretos, aproximadamente. Dentre as noventa organizações dos variados setores, trinta e quatro eram do segmento petroquímico. Com as fusões, muitas dessas organizações passaram a fazer parte de grupos como Braskem, Unigel e Ultra.

Em consonância com essas justificativas, as questões principais desta pesquisa são: Quais as mudanças em gestão de pessoas, realizadas pelas empresas petroquímicas, a partir da trajetória de diversificação no Complexo Industrial de Camaçari? Quais as estratégias e práticas que as diferentes organizações petroquímicas de Camaçari, diante das transformações ocorridas no pólo, vêm utilizando para atrair, reter e desenvolver seus profissionais? Como ocorre o alinhamento entre as integrações vertical e horizontal nessas organizações?

Os objetivos primordiais foram definidos como os de identificar e analisar quais as mudanças realizadas pelas empresas petroquímicas, a partir da trajetória de diversificação no Complexo Industrial de Camaçari, e os seus reflexos nas estratégias de atração, retenção e desenvolvimento de profissionais. Para tanto, foram definidos os seguintes objetivos específicos:

- Destacar as funções de gestão de recursos humanos, no sentido de identificar as influências do ambiente organizacional externo, da competição e da dinâmica do mercado de trabalho, como características do modelo de gestão estratégica de pessoas;

- Identificar as estratégias de atração, retenção e desenvolvimento de profissionais no segmento petroquímico, antes e depois das transformações ocorridas no Pólo; 
Gestão Estratégica de Pessoas nas Organizações Petroquímicas de Camaçari - Bahia: Seus Reflexos nas Estratégias de Atração, Retenção e Desenvolvimento de Profissionais

- Analisar as consequências das transformações no alinhamento entre as estratégias de gestão de pessoas e as estratégias dessas empresas petroquímicas do Pólo;

- Analisar as mudanças identificadas e os seus reflexos nas estratégias de atração, retenção e desenvolvimento de profissionais.

Os sujeitos desta pesquisa são diretores, gerentes e/ou coordenadores de RH, com tempo mínimo de experiência no pólo e em petroquímicas de 10 anos e máximo de 32 anos (com exceção de dois entrevistados com 3 anos e 2 anos e meio), dois entrevistados por organização, totalizando 42 entrevistas e 21 organizações. Contextualiza-se que foi realizada uma entrevista com o RH da Cetrel Central de Efluentes Líquidos, com a finalidade de se obter uma visão de fora das petroquímicas e, ao mesmo tempo, com conhecimento e experiência suficientes para contribuir com essa investigação.

Tal investigação foi respondida em cada categoria estabelecida para análise ('mudança de contexto'; 'estratégias de atração, retenção e desenvolvimento'; 'importância dessas estratégias'; 'estratégias específicas'; 'indicadores de contribuição'; ‘indicadores de alinhamento') e reforçada na junção de todas elas. Consolida-se a premissa de que tal investigação encerra, ao mesmo tempo, um aspecto inovador e contributivo para a área da gestão de pessoas, para o setor petroquímico e para o país.

\section{GESTÃO ESTRATÉGICA DE PESSOAS}

Antes de se falar em gestão estratégica de pessoas vale ressaltar que: a gestão de pessoas foi definida por Schuler (1992, p. 18) como “o conjunto de atividades que influenciam os comportamentos das pessoas em suas ações para formular e implementar as necessidades estratégicas do negócio"; Wrigth, Dunford \& Snell (2001), reforçaram o fato de a gestão de pessoas não se restringir apenas às funções tradicionais de RH, tais como recrutamento, seleção, treinamento, remuneração, etc., mas também ao fato de dever incorporar atividades relacionadas à comunicação, ao desenho do trabalho à cultura organizacional, ou à liderança, por exemplo; Lacombe (2005, p. 59) indicou que a gestão de pessoas incorpora "todas as atividades que influenciam as condições de realização do trabalho das pessoas, nos seus esforços de formulação, implementação e avaliação da estratégia organizacional"; Dutra (2002, p. 17) caracterizou a gestão de pessoas por "um conjunto de políticas e práticas que permitem a conciliação de expectativas

Revista Ibero-Americana de Estratégia - RIAE, São Paulo, v. 11, n. 3, p. 61-96, set./dez. 2012. 
entre a organização e as pessoas para que ambas possam realizá-las ao longo do tempo". Observa-se que esses conceitos, ainda que enunciados de modo diferente, se complementam em seus postulados.

Considerando-se que os últimos anos colocaram em evidência três enfoques teóricos sobre gestão de pessoas, quais sejam o comportamental, o estratégico e o articulado por competências, algumas linhas serão destinadas a tais enfoques, nesta fundamentação teórica.

O enfoque comportamental de gestão de pessoas, delineado a partir da década de 1960, realçou a importância do comportamento organizacional como campo de estudos e seus fatores como motivação, características pessoais dos empregados, estilos de liderança, sistemas de comunicação, estrutura de poder, cultura, organização do trabalho e estrutura organizacional, como influenciadores do comportamento e dos resultados organizacionais, com base em Ivancevih \& Matteson (1996).

No que tange ao enfoque estratégico, Anthony, Perrewé \& Kacmar (1996) enfatizaram que a gestão de pessoas assume um caráter estratégico quando: integra a estratégia de gestão de pessoas com a estratégia organizacional e demais estratégias funcionais; orienta suas ações para as pessoas em todos os níveis organizacionais e não somente para certos níveis ocupacionais; enfatiza a escolha e a tomada de decisão; apresenta foco de longo prazo; reconhece explicitamente os impactos do ambiente organizacional externo, da competição e da dinâmica do mercado. Ainda no enfoque estratégico Becker, Huselid \& Ulrich (2001) reforçaram que o caráter estratégico da gestão de pessoas pressupõe o alinhamento de recursos humanos com a estratégia maior da organização, em termos de missão, visão, estratégias, objetivos e planos.

Assim, a gestão de pessoas deixa de ocupar uma posição secundária em relação às decisões estratégicas da organização. Sob a perspectiva da administração estratégica de recursos humanos as pessoas passam a ser consideradas e tratadas como fontes de vantagem competitiva, mudando, em consequência, as estratégias que orientam o relacionamento entre as pessoas e a organização, de acordo com Fischer (1998) e Storey (2001). Entretanto, esse alinhamento não ocorre de forma simples e linear em todas as funções de recursos humanos. Pfeffer (1998) já enfatizava a necessidade de se criar condições necessárias para que todas as áreas funcionais identifiquem competências e comportamentos que as pessoas devem ter.

No que se reporta ao enfoque articulado por competências observa-se que ele preconiza que a área de recursos humanos, por reunir conhecimentos e informações sobre as pessoas nas organizações, passa a focar suas políticas e práticas na atração/aquisição, manutenção/retenção e desenvolvimento das competências individuais que possam viabilizar as competências 
Gestão Estratégica de Pessoas nas Organizações Petroquímicas de Camaçari - Bahia: Seus Reflexos nas Estratégias de Atração, Retenção e Desenvolvimento de Profissionais

organizacionais. Esse enfoque fornece um quadro referencial único para a gestão de pessoas e funciona como um eixo direcionador de todas as suas ações, que devem buscar o maior alinhamento possível com as estratégias organizacionais, na concepção de autores como McLagan (1980); Lado \& Wilson (1994); Wright, at. al. (2001); Lacombe (2005).

De acordo com Giannantonio \& Hurley (2002), dois aspectos dessas mudanças são especialmente relevantes: os profissionais de RH enfrentam um conjunto de questões cada vez mais complexo na prática diária de seus trabalhos; nessa nova realidade os papeis que os departamentos de RH desempenham nas organizações têm mudado de uma função puramente administrativa para outra que inclui se tornar parceiro estratégico preocupado em adicionar valor à organização.

Tais aspectos puderam ser corroborados por Martín-Alcázar, Romero-Fernádez \& SánchezGardey, (2008) quando enfatizaram que a gestão de recursos humanos começou a ser considerada uma ampla função, que abrange estratégias, políticas, práticas e filosofias globais de gestão de pessoas. Respaldando-se nesses autores, a gestão estratégica de pessoas pode ser compreendida como uma forma mais ampla de entender a gestão de pessoas. Quanto ao nível de análise esses autores conceituaram a gestão de pessoas de duas formas: uma orientação micro, centrada em questões funcionais; uma macro, que a analisa sob uma perspectiva estratégica.

A pesquisa que ora se desenvolve tem sua gênese no conceito de gestão estratégica de recursos humanos, que preconiza que as políticas de gestão de pessoas devem ser parte integrante das estratégias de negócios da empresa. Anthony et al. (1996) destacaram a capacidade da área de recursos humanos, no sentido de reconhecer e identificar os impactos do ambiente organizacional externo, da competição e da dinâmica do mercado de trabalho como uma das principais características do modelo de gestão estratégica de pessoas.

Com o surgimento dessa idéia de se incluir e alinhar a gestão de pessoas à estratégia, a administração de recursos humanos ganhou novo impulso para demonstrar seu valor na organização e passou a exercer o papel de gerenciar as pessoas apoiando-se na estratégia organizacional. A administração estratégica é compreendida como um processo amplo que abrange a visão, a formulação e a implementação, bem como a avaliação dos resultados, tendo em vista orientar e empreender ações estratégicas. Em decorrência, a gestão estratégica é condicionada pela visão dos atores organizacionais envolvidos no processo.

Do ponto de vista desses atores organizacionais, Dutra (2004) enfatizou que um sistema de gestão de pessoas, integrado e estratégico, carreia maior sinergia entre suas partes e faz com que os vários processos de gestão do sistema se reforcem mutuamente, o que garante a esse sistema maior efetividade, coerência e consistência. E, para que a gestão de pessoas crie valor agregado à 
organização, ela precisa tornar-se uma parceira do negócio na busca dos objetivos estratégicos, como ressaltado por: Schuler \& Jackson (1987); Mabey, Skinner \& Clark (1998).

Nesse processo de criação de valor para a organização, Ulrich (1998) propôs um modelo de múltiplos papeis desempenhados pelos profissionais de RH utilizando-se de dois eixos: o do foco que vai do estratégico de longo prazo ao operacional de curto prazo e o eixo das atividades que se estendem da administração de processos à administração de pessoas.

Nesse modelo, quatro papeis de RH foram definidos: administração de estratégias da organização, cujo papel é o de participar do processo de definição da estratégia geral e concepção de estratégias e práticas de gestão de pessoas a ela integradas, transformando o profissional de RH em parceiro estratégico da organização; administração de infraestrutura da organização, cujo papel tradicional do especialista administrativo consiste em conceber e desenvolver processos eficientes para contratar, treinar, avaliar, premiar, promover e gerir o fluxo de empregados na organização; administração da contribuição dos colaboradores, em que o papel do defensor dos funcionários é enfatizado e cuja meta é obter maior envolvimento e competência do quadro de pessoal, por intermédio da provisão de recursos necessários aos empregados; administração da transformação e da mudança que tem por objetivo desenvolver capacidades para mudança organizacional, transformando o profissional de RH em agente de mudança.

Ressalta-se que esses papeis estão alinhados com a perspectiva de macro análise da gestão de pessoas. Mesmo considerando a importância da integração das políticas da administração de recursos humanos há de ser também considerado o tratamento das pessoas com relação às questões de comprometimento, adaptabilidade e alta qualidade, preconizadas por Guest (1987). As organizações, desde então, parecem estar, cada vez mais, tendendo a voltar-se para a humanização e o desenvolvimento, imprimindo mais liberdade e consciência à sua força de trabalho.

Alinhada a tal pensamento, Casado (2002a) relembrou características essenciais dos indivíduos no contexto organizacional, tais como necessidades, interesses, sonhos, potencialidades e limitações, indivisibilidade. A autora reiterou que o significado de tais características parece estar definitivamente incorporado às políticas e ações contemporâneas de gestão de pessoas.

Nessa mesma linha de pensamento e, não obstante ainda possam ser encontrados, na prática, profissionais de recursos humanos presos às funções operacionais como folha de pagamento, às questões burocráticas e posturas rígidas sustentadas por inúmeros controles burocráticos, para Marras (2000), o padrão exigido para o gestor de recursos humanos deveria englobar: visão holística; perfil de planejador estratégico; estilo de liderança situacional; formação humanista dotada de uma profunda empatia para estabelecer relações proveitosas, tanto com os executivos da organização como com os

Revista Ibero-Americana de Estratégia - RIAE, São Paulo, v. 11, n. 3, p. 61-96, set./dez. 2012. 
Gestão Estratégica de Pessoas nas Organizações Petroquímicas de Camaçari - Bahia: Seus Reflexos nas Estratégias de Atração, Retenção e Desenvolvimento de Profissionais

trabalhadores de chão de fábrica. Observa-se que tais padrões também estão inseridos na perspectiva de macroanálise da gestão contemporânea de pessoas.

Há algum tempo já vem sendo observada uma evolução do conceito de administração estratégica de recursos humanos, que resulta da crescente necessidade de orientação para planejamento e de intervenções gradativas com orientações estratégicas, conforme discutido por Davel \& Vergara (2001). No entanto, não basta que o gestor identifique uma visão coerente e atraente da organização. Faz-se necessário comunicá-la nos variados níveis organizacionais, sustentando a interação entre as pessoas e a organização.

Essa visão precisa ser transmitida por meio de persuasão e inspiração, em lugar de edição ou coerção, considerando-se os valores organizacionais, objetivos e metas, filosofia de atuação. Uma vez transmitida, a visão precisa ser reforçada pelas decisões e ações de apoio do gestor. Casado (2002b) afirmou a importância do papel do gestor, na identificação dos norteadores de comportamento de seus subordinados, no reconhecimento da natureza intrínseca e individual da motivação desses indivíduos e na gestão em direção à energia que naturalmente se encontra dentro de cada um deles. A autora afiançou a necessidade de tudo isso ocorrer de modo compatível com os objetivos da organização e com o crescimento de cada integrante. Autores como Becker, et. al. (2001) argumentaram que os profissionais de RH estão aptos para contribuir com os gestores, ao exercerem o papel de parceiros estratégicos e agregar valor à organização.

Assim sendo, é exigida participação mais ampla de colaboradores de diferentes níveis da organização na formulação da estratégia como uma forma de tornar o processo estratégico mais interativo e contínuo, estimulando a comunicação, o aprendizado e o comprometimento das pessoas. No que tange à participação dos profissionais de RH na formulação da estratégia, diversos autores, já há algum tempo, entendiam ser esse o novo papel do RH, a exemplo de Anthony, et. al. (1996); Ulrich (1998); Becker, et. al. (2001).

Analisada do ponto de vista de função, a gestão de pessoas tem sido cada vez mais apontada como uma das funções-chave para o desenvolvimento e implementação de respostas estratégicas por estudiosos como Ulrich (1997); Yeung \& Berman (1997); Ulrich et al (2011); Ulrich \& Ulrich (2011). A estratégia de gestão de pessoas pode ser estudada tomando-se como indicadores as práticas ou funções de gestão de pessoas. Essas práticas ou funções consistem em atividades que compõem a estratégia nas organizações. Ulrich \& Ulrich (2011, p. 223) chamaram a atenção para o fato de que "[...] as práticas de $\mathrm{RH}$ formam a infraestrutura que proporciona o sucesso organizacional sustentável”.

Revista Ibero-Americana de Estratégia - RIAE, São Paulo, v. 11, n. 3, p. 61-96, set./dez. 2012. 
Esse movimento transformador, como apontado por Lawler III (1991, p. 12) estimulou as "mudanças organizacionais de larga escala", que promoveram expressivas alterações no design organizacional, nas estratégias de negócios e, em conseqüência, no sistema de gestão de pessoas. De acordo com o autor, esse tipo de mudança implica transformação duradoura, por localizar-se no bojo do caráter organizacional e por modificar profundamente o seu desempenho e o modo de operação.

Entretanto, há de se atentar para uma diversidade no pensamento do especialista de recursos humanos, que contribui para a heterogeneidade ainda observada nas práticas de gestão de RH entre as organizações nacionais. Existem aquelas que mantêm uma abordagem mais operacional, as que adotam uma abordagem mais estratégica e aquelas que se aproximam de uma abordagem mais competitiva (Lacombe \& Tonelli, 2000).

Nota-se, contudo, tanto na prática da administração quanto nos estudos científicos de Martín-Alcázar, Romero-Fernández \& Sánchez-Gardey (2005; 2008); Lepak \& Shaw (2008); Lacombe \& Albuquerque (2008); Albuquerque \& Leite (2009); Lengnick-Hall, M. L, LengnickHall, C. A., Andrade \& Drake (2009) que, em seus temas contemporâneos, a gestão estratégica de pessoas abarca questões de tendências como: avaliação de resultados organizacionais em gestão de pessoas; gestão do terceiro setor; governança corporativa; transformações no mercado de trabalho; inovação conectada à gestão de pessoas; gestão para a sucessão de profissionais; internacionalização das organizações; gestão estratégica de carreira. Tal constatação está alinhada ao que salientaram Ulrich et. al. (2011, p. 31) sobre "os profissionais de RH que querem contribuir com a formulação de uma estratégia e sustentar uma transformação deveriam ser mais que observadores dessas tendências".

Em meio às tendências, observa-se que a trajetória evolutiva da transformação da administração de recursos humanos para a gestão estratégica de pessoas continua despertando interesse de pesquisadores brasileiros, a exemplo de Lacombe \& Chu (2008); Mascarenhas, (2008); Leite \& Albuquerque (2009); Leite \& Albuquerque (2009a); Leite \& Albuquerque (2009b); Tanure, Evans \& Cançado (2010); Leite \& Albuquerque (2010); Leite, Albuquerque \& Kniess (2010); Leite \& Albuquerque (2011).

Revista Ibero-Americana de Estratégia - RIAE, São Paulo, v. 11, n. 3, p. 61-96, set./dez. 2012. 
Gestão Estratégica de Pessoas nas Organizações Petroquímicas de Camaçari - Bahia: Seus Reflexos nas Estratégias de Atração, Retenção e Desenvolvimento de Profissionais

\section{ATRAÇÃO, RETENÇÃo E DESENVOLVIMENTO DE PESSOAS}

Reitera-se que, no contexto contemporâneo o ambiente organizacional é caracterizado por transformações rápidas, profundas e constantes. Mudanças tecnológicas, globalização da economia, acirramento da competição entre organizações e entre países e diversidade da força de trabalho são alguns fatores que influenciam significativamente a gestão das organizações.

Tais fatores têm exigido que essas organizações se tornem capazes de captar, reter e desenvolver profissionais aptos a adaptar-se às exigências do meio no qual atuam. Do mesmo modo, a sensibilidade para pesquisar e perceber mudanças no ambiente externo à organização já vem sendo apontada como relevante para a obtenção de respostas estratégicas por parte das pessoas que atuam com recursos humanos.

Essas transformações no mundo do trabalho, assim como os desafios que continuam sendo trazidos para as organizações, exigem que a área de recursos humanos assuma papel fundamental não apenas na definição e execução de ações estratégicas de atração, mas também na retenção e no desenvolvimento desses profissionais. As organizações bem-sucedidas são aquelas que conseguem atrair, reter, desenvolver e compensar profissionais responsáveis tanto por clientes, quanto pelo gerenciamento de crescentes oportunidades tecnológicas, conforme salientado por Ulrich (1998).

O desenvolvimento de competências, a atração, retenção e desenvolvimento de trabalhadores altamente qualificados, onde quer que eles estejam localizados no mundo, estão entre as formas mais comuns que os profissionais de gestão de pessoas planejam responder a essas transformações, por meio de iniciativas de treinamento, educação e aprendizagem, conforme salientado por Friedman (2007).

Em seu estudo sobre a estratégia de retenção de profissionais, Chew (2004) agrupou dois conjuntos de fatores que favorecem a prática de retenção de funcionários centrais de organizações australianas: fatores de gestão de pessoas (ajuste entre pessoas e organização, remuneração, reconhecimento e recompensa, treinamento e desenvolvimento de carreira, oportunidades de trabalho desafiadoras); fatores organizacionais (atitude da liderança, políticas e cultura da organização, relacionamento entre integrantes da equipe de trabalho e ambiente de trabalho satisfatório).

Outro aspecto a ser considerado no esforço organizacional de atrair, desenvolver e reter pessoas é o da capitalização das competências individuais que agregam valor aos grupos e à organização. Para os pesquisadores que tratam da gestão de pessoas segundo o conceito de competência, a área de recursos humanos deve assumir um papel importante no desenvolvimento da

Revista Ibero-Americana de Estratégia - RIAE, São Paulo, v. 11, n. 3, p. 61-96, set./dez. 2012. 
estratégia da organização, à medida que cuida com mais propriedade de atrair, manter e desenvolver as competências necessárias à realização dos objetivos organizacionais. Esses pesquisadores observaram que, a discussão sobre gestão de competências, como alternativa da área de recursos humanos para sua legitimação, na esfera decisória e estratégica, impõe, aos profissionais de recursos humanos, o desafio de comprovar sua efetividade com resultados tangíveis para a organização (Fleury \& Fleury, 2004; Barbosa, Ferraz \& Ávila, 2004).

Por seu turno, o reporte do conhecimento como ativo estratégico reforça a ideia de que a gestão de pessoas deve ser colocada em alinhamento com a estratégia da organização. Estudiosos como Fleury \& Fleury (2004), Dutra (2004), entre outros, também consideraram que a área de recursos humanos deve assumir um papel importante no desenvolvimento dessa estratégia, na medida em que cuida, com mais propriedade, de atrair, manter e desenvolver as competências necessárias à realização dos objetivos organizacionais. Isso implica comprovar a efetividade dos profissionais de $\mathrm{RH}$, com resultados tangíveis.

\section{METODOLOGIA DA PESQUISA}

Este tópico engloba os sujeitos da pesquisa, a abordagem metodológica utilizada, as categorias de análise definidas, as estratégias de coleta e de análise dos dados, bem como a contextualização do campo de estudo.

Quanto aos sujeitos da pesquisa foram envolvidos diretores, gerentes e/ou coordenadores de RH. Esses respondentes têm tempo mínimo de experiência no pólo e em petroquímicas de 10 anos e máximo de 32 anos. Com média de dois entrevistados por organização, totalizam-se vinte e uma organizações petroquímicas estudadas, incluindo a Cetrel - Central de Efluentes Líquidos, com a finalidade de se obter uma visão de fora das petroquímicas e, ao mesmo tempo, com conhecimento e experiência suficientes (mais de 21 anos) para contribuir com essa investigação.

No que se refere à abordagem metodológica, nesta pesquisa o posicionamento metodológico envolve pressupostos adotados sobre a natureza da realidade (ontológicos) e sobre a natureza do conhecimento (epistemológicos), em que a abordagem metodológica está inserida na pesquisa qualitativa, tomando-se por base Chizzotti (2008) e o significado de partilha com pessoas, fatos e locais que constituem objetos de estudo. Adotou-se o método fenomenológico de investigação crítica, criteriosa, rigorosa e sistemática, como alerta de Moreira (2004) para os riscos de interpretação na transposição desse método, da filosofia para a pesquisa empírica.

Revista Ibero-Americana de Estratégia - RIAE, São Paulo, v. 11, n. 3, p. 61-96, set./dez. 2012. 
Gestão Estratégica de Pessoas nas Organizações Petroquímicas de Camaçari - Bahia: Seus Reflexos nas Estratégias de Atração, Retenção e Desenvolvimento de Profissionais

Tal fato justifica-se, neste estudo por ser esse método reconhecido como uma abordagem à pesquisa qualitativa, em vários campos de estudos, dentre eles a Administração, principalmente por seu caráter intrinsecamente interdisciplinar e dialógico com as demais áreas de conhecimentos e disciplinas que ajudam a compreender o fenômeno estudado.

No que diz respeito às categorias de análise, para esta pesquisa relembre-se, ainda, que os objetivos primordiais foram definidos como os de identificar e analisar quais as mudanças realizadas pelas organizações petroquímicas, a partir da trajetória de diversificação no Complexo Industrial de Camaçari e os seus reflexos nas estratégias de atração, retenção e desenvolvimento de profissionais. Para tanto, foram investigadas vinte e uma organizações dentre as que compõem o segmento petroquímico do complexo industrial de Camaçari, envolvendo, além de organizações individuais, os grupos: Braskem, Unigel e Ultra.

Tal investigação foi realizada considerando seis categorias estabelecidas a priori e ajustadas a posteriori para análise: 'mudança de contexto'; 'estratégias de atração, retenção e desenvolvimento'; 'importância dessas estratégias'; 'estratégias específicas'; 'indicadores de contribuição'; ‘indicadores de alinhamento’ e reforçada na junção de todas elas.

No que tange à coleta de dados, o período previsto para realizar as entrevistas em profundidade, com duração média de duas horas e meia cada, se mostrou congruente. Foi realizado um pré-teste do roteiro de entrevistas com um representante de cada uma dessas organizações, com vistas aos ajustamentos necessários.

As observações foram realizadas nos locais dessas organizações, quando visitadas para a realização das entrevistas, desde o ritual de entrada. Essas observações foram realizadas em consonância com a recomendação de Eisenhardt (1989) e Einsenhardt \& Graebner (2007), utilizando-se a combinação das seguintes fontes de evidência, na formação da triangulação: entrevistas, observações e análise de documentos sobre especificidades da organização petroquímica dentro de um complexo industrial.

Para a análise dos dados, foram tomados por base, inicialmente, Cooper \& Schindler (2003). Ademais, foram utilizadas: análise de conteúdo, com base em Bardin (2010) e Selltiz, Wrightsman \& Cook (2005); metodologia reflexiva, de acordo com Vergara (2005), segundo a qual, fundamentação teórica e coleta de dados empíricos caminham conjuntamente; análise documental de especificidades petroquímicas.

Ressalte-se que, nesta pesquisa: a análise de conteúdo das entrevistas, nas seis categorias definidas, apoiou-se, predominantemente, em procedimentos interpretativos; a metodologia reflexiva, com base em Vergara (2005), foi utilizada para a interpretação dos dados empíricos

Revista Ibero-Americana de Estratégia - RIAE, São Paulo, v. 11, n. 3, p. 61-96, set./dez. 2012. 
oriundos das entrevistas, observações e para a interpretação das bases teóricas que respaldaram a análise da pesquisa empírica. A análise de conteúdo foi realizada com base em frases-chave registradas em protocolo de entrevista, categorizadas para a análise do conjunto de entrevistas, conforme recomendado por Bardin (2010) e Vergara (2005). A triangulação mostrou a importância de se efetuar cruzamento de dados oriundos de diversas fontes de evidência, buscando-se, em consequência, melhor entendimento do fenômeno estudado.

À guisa de retomada da contextualização do campo de estudo relembre-se que o Pólo Petroquímico de Camaçari, Estado da Bahia, criado em 1978, é o primeiro complexo petroquímico planejado do país. Ainda hoje, esse complexo industrial é responsável por parte do desenvolvimento da cidade de Camaçari e por $30 \%$ do PIB da Bahia, desde sua implantação como unidade de produção petroquímica, até sua transformação no maior complexo industrial integrado do Hemisfério Sul (Cofic - Comitê de Fomento Industrial de Camaçari, 2008).

A atração de novos empreendimentos gerou um novo ciclo de expansão, com mais oportunidade de emprego e renda para o Nordeste. De acordo com o Presidente do Cofic (2008), um trabalho realizado por sete grupos formados por representantes das organizações do setor petroquímico e do governo do Estado da Bahia, representado pela Secretaria da Indústria, Comércio e Mineração, "traduz a essência de um trabalho conjunto e cristaliza os anseios para a consolidação do futuro do Pólo".

O trabalho citado apresentou resultados marcadamente concernentes ao segmento petroquímico: a infraestrutura e logística estão marcadas por colapsos e ineficiências em portos, rodovias e ferrovias; há escassez de matéria- prima como nafta e gás natural; é destacada a ausência de projetos inovadores que resultem em desdobramentos e novas fábricas nos últimos quatro anos; há perda de densidade industrial, percepções de estagnação e desenvolvimento, situação destoante do que se apresenta em São Paulo, Rio Grande do Sul e Rio de Janeiro, locais onde também são registrados pólos de atividades petroquímicas.

Superar os desafios estruturais e conjunturais que ameaçam a competitividade do Pólo Industrial de Camaçari, transformando-os em oportunidades para um crescimento sustentável de suas atividades nas próximas décadas, é a sua meta principal. Esse Pólo tem como visão continuar servindo à Bahia e ao Brasil, com elevado desempenho operacional, excelência organizacional/empresarial e responsabilidade socioambiental, gerando oportunidades de emprego, renda e riqueza para o País (Cofic, 2008).

Revista Ibero-Americana de Estratégia - RIAE, São Paulo, v. 11, n. 3, p. 61-96, set./dez. 2012. 
Gestão Estratégica de Pessoas nas Organizações Petroquímicas de Camaçari - Bahia: Seus Reflexos nas Estratégias de Atração, Retenção e Desenvolvimento de Profissionais

A Figura 1 mostra a composição atual das organizações petroquímicas de Camaçari em que: o grupo Braskem é composto por oito antigas organizações individuais; o grupo Unigel, por quatro organizações e o grupo Ultra por duas.

Figura 1 - Composição atual das organizações petroquímicas de Camaçari.

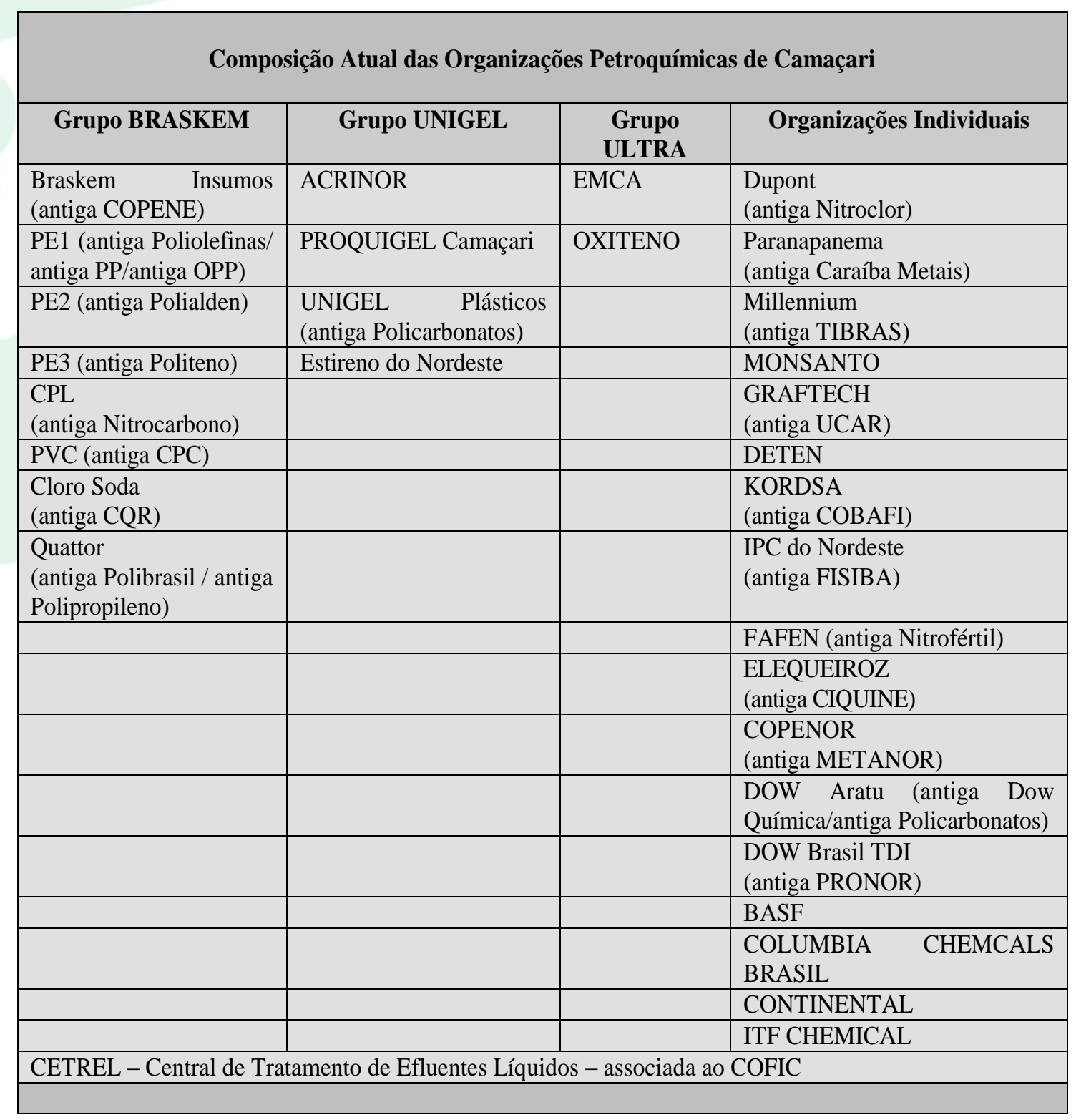

Fonte: Elaborado pelos autores.

Revista Ibero-Americana de Estratégia - RIAE, São Paulo, v. 11, n. 3, p. 61-96, set./dez. 2012. 


\section{APRESENTAÇÃO E ANÁLISE DOS DADOS E DISCUSSÃO DOS RESULTADOS}

Este tópico mostra a apresentação e análise dos dados por intermédio das seis categorias estabelecidas para análise: 'mudança de contexto'; 'estratégias de atração, retenção e desenvolvimento'; 'importância dessas estratégias'; 'estratégias específicas'; 'indicadores de contribuição'; 'indicadores de alinhamento'. Para a discussão dos resultados os dados analisados pelos conteúdos das entrevistas foram confrontados com a fundamentação teórica da pesquisa. Para a análise de conteúdo das entrevistas foram tomadas por base frases-chave registradas em protocolos de entrevistas.

Essas categorias são mostradas nas Figuras 02, 03, 04, 05, 06 e 07 e ajudam a destacar os objetivos específicos, bem como responder às questões de pesquisa formuladas. No que tange aos objetivos principais, definidos como os de identificar e analisar as mudanças realizadas pelas organizações petroquímicas, cada uma dessas figuras vai ajudando a tecer as considerações que levam à realidade dessas petroquímicas, conforme percebida pelos respondentes.

Os dados aqui apresentados e analisados buscam responder às questões principais, formuladas nesta pesquisa, à luz dos dados coletados em entrevistas, observações e análise de documentos, bem como da fundamentação teórica desta pesquisa.

Quais as mudanças em gestão de pessoas, realizadas pelas empresas petroquímicas, a partir da trajetória de diversificação no Complexo Industrial de Camaçari?

Quais as estratégias e práticas que as diferentes organizações petroquímicas de Camaçari, diante das transformações ocorridas no pólo, vêm utilizando para atrair, reter e desenvolver seus profissionais? Como ocorre o alinhamento entre as integrações vertical e horizontal nessas organizações?

A categoria 1 trata da mudança de contexto do Pólo Petroquímico de Camaçari para Complexo Industrial de Camaçari. A Figura 2 apresenta os dados referentes à categoria 'mudança de contexto'. Essa figura, também mostra identificação de algumas influências do ambiente organizacional externo, da competição e da dinâmica do mercado de trabalho, como características importantes para o modelo de gestão estratégica de pessoas nessa realidade petroquímica.

Diante dos dados dessa Figura e, recorrendo-se à literatura, de acordo com Marras (2000) observa-se que as razões para a migração da administração de recursos para a administração estratégica de recursos humanos estão atreladas a: globalização dos mercados e seus desdobramentos nas organizações; mudança na filosofia de vida; mudanças de paradigmas que modificam, substancialmente, o rumo dos resultados organizacionais e o perfil cultural das organizações.

Revista Ibero-Americana de Estratégia - RIAE, São Paulo, v. 11, n. 3, p. 61-96, set./dez. 2012. 
Gestão Estratégica de Pessoas nas Organizações Petroquímicas de Camaçari - Bahia: Seus Reflexos nas Estratégias de Atração, Retenção e Desenvolvimento de Profissionais

Figura 2 - Categoria 1 - mudança de contexto.

\section{CATEGORIA 1- MUDANÇA DE CONTEXTO}

\section{Questão norteadora:}

A mudança de contexto do Pólo Petroquímico de Camaçari para Complexo Industrial de Camaçari foi percebida como relevante para nortear as políticas e práticas da gestão de pessoas nas organizações petroquímicas?

A questão norteadora dessa categoria foi assim respondida pelos entrevistados, registrando-se os pontos comuns:

Houve e ainda há busca de sinergia no processo de integração de plantas petroquímicas para tornar os custos compatíveis, além de suprimir os altos custos de plantas isoladas.

Considera-se o aumento das petroquímicas no mundo como outro dado relevante para nortear as mudanças de contexto das organizações petroquímicas de Camaçari.

A mudança de contexto foi benéfica, pois tirou as organizações petroquímicas da zona de conforto, além de ter favorecido tanto a interação quanto o enriquecimento do mercado local.

Entretanto...

As mudanças com as petroquímicas começaram a acontecer antes da trajetória de diversificação no Complexo Industrial de Camaçari, com os processos de terceirizações, fusões e incorporações dessas petroquímicas.

Fonte: Elaborado pelos autores.

A história do Pólo teve iniciou na década de 1970 com modelo tripartite e envolvimento da Petroquisa. O mercado era fechado e sem preocupação com a concorrência. Mais tarde, ocorreu a saída dos grupos estrangeiros, ficando os grupos nacionais e a Petroquisa. A Holding / Norquisa congregava acionistas nacionais, com o objetivo de desenvolver o complexo. Nessa década não existia mão-de-obra local e a Universidade Federal da Bahia - UFBA / Escola Técnica Federal formavam as pessoas nas áreas de Química e Engenharia Química. No início da década de 1990, com a abertura comercial, as empresas brasileiras, em particular as petroquímicas, começaram a sentir mais contundentemente as pressões por mudanças.

A partir de então, observou-se um movimento de elevação dos padrões tecnológicos, reestruturações, privatizações, racionalizações, ampliações, fusões, aquisições e profissionalização da gestão. Tudo isso, no bojo de iniciativas voltadas à: elevação da eficiência das empresas; melhoria do desempenho; otimização dos resultados dos negócios; obtenção de diferenciação; recuperação do atraso em relação aos países de economia mais desenvolvida.

Nessa mesma década, na literatura, esse movimento transformador foi apontado por Lawler III (1991, p. 12) como o que estimulou as "mudanças organizacionais de larga escala", que 
promoveram expressivas alterações no design organizacional, nas estratégias de negócios e, em consequência, no sistema de gestão de pessoas. De acordo com o autor, esse tipo de mudança implica transformação duradoura, por localizar-se no bojo do caráter organizacional e por modificar profundamente o seu desempenho e o modo de operação.

Registra-se que, ainda na década de 1990 as petroquímicas foram transformadas em unidades fabris, com sistemas administrativos localizados no Rio de Janeiro e em São Paulo, caracterizando-se uma modificação significativa no modo de operação. A finalidade dessa transformação era esvaziar e reduzir custos.

A abertura do mercado petroquímico internacional nos anos 1990 representou um salto tecnológico importante. Foi preciso, então, cuidar da concepção de recursos humanos, começandose por entender o significado estratégico do sistema de gerir pessoas.

Nos anos 2000, com a chegada da indústria automotiva foi-se consolidando a formação de mão-de-obra petroquímica pela Petrobras. A Ufba permaneceu contribuindo com a Engenharia Elétrica e a Mecatrônica.

Atualmente a Petrobras treina grupos de técnicos, o Senai e o Cofic formam grupos de operações. A mão de obra petroquímica é específica e há uma estratégia cooperativa para capacitação de operadores das organizações petroquímicas e químicas.

O foco do Pólo Industrial é diferente do Petroquímico. Houve, por um período, evasão interna no nível de gerenciamento. A chegada da Ford muito pouco influenciou no nível operacional, em razão das especificidades. Ela trouxe o benefício de usar a mão de obra da cidade de Camaçari. A competitividade externa influenciou o processo de mudança.

A categoria 2 aborda as estratégias de atração, retenção e desenvolvimento de pessoas. Investigando-se as implicações do mercado de trabalho para a gestão estratégica de pessoas, como visto na literatura contemporânea que fundamentou esta pesquisa, ficou destacada a importância, entre outras variáveis, do capital humano e da atração e retenção de profissionais talentosos nas organizações, no cenário de crescente flexibilização desse mercado, não mais sob a égide do trabalho rotineiro e desqualificado que prevaleceu durante o fordismo.

A abordagem de Ulrich \& Ulrich (2011) acerca das práticas de RH como formadora da infraestrutura e proporcionadora do sucesso organizacional sustentável também é aqui ressaltada. A Figura 3 contém os dados concernentes à categoria 'atração, retenção e desenvolvimento', identificando tais estratégias no segmento petroquímico, antes e depois das transformações ocorridas no Pólo.

Revista Ibero-Americana de Estratégia - RIAE, São Paulo, v. 11, n. 3, p. 61-96, set./dez. 2012. 
Gestão Estratégica de Pessoas nas Organizações Petroquímicas de Camaçari - Bahia: Seus Reflexos nas Estratégias de Atração, Retenção e Desenvolvimento de Profissionais

Figura 3 - Categoria 2 - estratégias de atração, retenção e desenvolvimento.

\section{CATEGORIA 2- ESTRATÉGIAS DE ATRAÇÃO, RETENÇÃo E DESENVOLVIMENTO}

\section{Questão norteadora:}

Como essa mudança de contexto influenciou as estratégias de atração, retenção e desenvolvimento nas organizações petroquímicas?

Com a questão norteadora dessa categoria, os entrevistados reforçaram que:

A gestão de pessoas passou a ser considerada estratégica, a partir da mudança de contexto, uma vez que, ao serem tiradas da zona de conforto as organizações petroquímicas cuidaram de observar melhor as estratégias de atração, retenção e desenvolvimento das pessoas;

As políticas de recursos humanos passaram a assumir como premissa básica, a valorização dos talentos humanos; A atração e a manutenção de pessoas de alto potencial e qualificação para o trabalho passaram a ser olhadas com foco no comportamental;

A criação de condições favoráveis à motivação individual e à mobilização dos grupos em torno das metas organizacionais passou a ser mais reforçada;

A possibilidade de desenvolvimento profissional na própria organização passou a ser considerado um desafio maior.

Entretanto...

A disponibilização de incentivos vinculados a resultados obtidos pela equipe e adaptação de políticas integradas de recursos humanos à realidade da organização e ao seu contexto de atuação continua como alvo a ser mantido por essas petroquímicas.

Fonte: Elaborado pelos autores.

As entrevistas mostraram que a capacitação diferenciada, incluindo educação, ajuda na retenção dos profissionais, em que interação e respeito são exigidos na forma de gerir pessoas. Atualmente a formação desses profissionais é de responsabilidade específica das organizações petroquímicas, uma vez que as universidades estão distantes. O Cofic integra as ações de formação, envolvendo todas as organizações associadas. O projeto de formação tem significância para o mercado, pois o nível de aproveitamento dos participantes é alto e os egressos desse projeto são disputados pelas organizações.

No que tange à estratégia de atração, os entrevistados lembram que no início das atividades do Pólo Petroquímico os salários eram diferenciados. Há semelhança atual entre as químicas e as petroquímicas e os salários ainda permanecem acima da média de mercado. O pacote de benefícios, 
principalmente com a previdência privada, transporte, alimentação, é considerado de excelência, embora menos atrativo que outrora. Existe a participação em lucros e resultados.

No que se diz respeito à gestão de pessoas, nessa estratégia, foi mencionada entre os entrevistados a remodelação na forma de atrair talentos, com novo olhar para o processo seletivo. Nessa remodelação ocorreu a saída do processo de selecionar e recrutar com foco nas competências técnicas, para o processo de selecionar e recrutar com base em valores e características alinhadas aos valores e premissas da organização. Há unanimidade quanto à informação de que continua o mesmo rigor no recrutamento, visto há trinta anos. Do mesmo modo, que ainda há a visão de petroquímica como elite, o que permanece atraindo, espontaneamente, a mão de obra especializada.

No que se refere à estratégia de retenção, os entrevistados afirmaram a existência de: plano de carreira, sucessão, o próprio pacote de benefícios, mantido no patamar desejado, remuneração variável, preparação para aposentadoria. Por outro lado, há também os desafios com a Geração Y, em que os engenheiros vão para o pólo industrial. Como dado curioso foi registrado que, o concurso Petrobras representa um chamariz, por conter aspectos de segurança e estabilidade, contrariando o comportamento dessa Geração Y. Foi enfatizado que esse concurso constitui a maior fonte de perda dessa mão de obra. As pessoas antigas são chaves, responsáveis diretas pelo desenvolvimento, por isso elas estão no foco de atenção nessa estratégia.

No que concerne à estratégia de desenvolvimento, o nível técnico permanece com possibilidade de treinamento no exterior e há respeito às competências das pessoas em todos os níveis. Novamente as pessoas da Geração Y foram citadas como desafios, pois, sendo oito anos o tempo necessário para desenvolver pessoas, em níveis técnico e operacional para as petroquímicas, essas pessoas, donas de suas carreiras, não mais esperam tanto tempo. O processo de desenvolvimento, atualmente é desenhado em conjunto com essas pessoas.

Retomando a fundamentação teórica desta pesquisa relembra-se o que Friedman (2007) salientou a respeito do desenvolvimento de competências, da atração, retenção e desenvolvimento de trabalhadores altamente qualificados, figurados entre as formas mais comuns que os profissionais de gestão de pessoas podem responder às transformações no mundo do trabalho.

A categoria 3 indica a importância das estratégias de atração, retenção e desenvolvimento para as petroquímicas investigadas. Ao discorrerem sobre os significados da administração de recursos humanos na conquista (atração) e retenção de profissionais talentosos na organização, Leite \& Albuquerque (2009) enfatizaram que esses significados têm pesos distintos: a conquista pode vir a ser realizada por vias efêmeras no curto prazo; a retenção exige vias como valores pautados na confiança, respeito, responsabilidade e maestria, tanto no curto, quanto no longo e

Revista Ibero-Americana de Estratégia - RIAE, São Paulo, v. 11, n. 3, p. 61-96, set./dez. 2012. 
Gestão Estratégica de Pessoas nas Organizações Petroquímicas de Camaçari - Bahia: Seus Reflexos nas Estratégias de Atração, Retenção e Desenvolvimento de Profissionais

médio prazos, para que objetivos e metas possam ser atingidos, assim como as políticas e práticas de gestão de pessoas estejam alinhadas às estratégias do negócio.

A Figura 04 mostra os dados relativos à categoria 'importância dessas estratégias', identificando os pesos atribuídos a essas estratégias antes e depois das transformações ocorridas.

Figura 4 - Categoria 3 -importância dessas categorias.

\section{CATEGORIA 3- IMPORTÂNCIA DESSAS ESTRATÉGIAS}

\section{Questão norteadora:}

Foram atribuídos pesos distintos para as estratégias de atração, retenção e desenvolvimento pelas organizações petroquímicas?

A questão norteadora dessa categoria ficou assim respondida:

Todos os entrevistados enfatizaram que as estratégias de atração, retenção e desenvolvimento de pessoas são estudadas e operacionalizadas integradamente;

Para uma parte dos entrevistados, há maior ênfase na retenção dos talentos antigos;

Com o modelo de Pólo, semiconfinado, fica dificultada a retenção da Geração Y, que prefere as facilidades da cidade e, nesse caso, é também atribuído peso maior para a estratégia de retenção;

Outra parte dos entrevistados enfatizou que o peso maior recai sobre desenvolvimento, uma vez que atração e retenção fazem parte da tradição das organizações petroquímicas.

Entretanto...

A área de recursos humanos, nessas petroquímicas, ainda precisa redefinir seu papel, não apenas no delineamento e execução de ações estratégicas de atração, mas também na retenção e no desenvolvimento desses profissionais.

Fonte: Elaborado pelos autores.

No estudo integrado das estratégias de atração, retenção e desenvolvimento, o foco na atenção à estratégia de retenção, para uma parte dos entrevistados, deveu-se ao mapeamento quanto à necessidade de: revisão e implementação de novos processos administrativos; desenho e implementação de nova estrutura organizacional; revisão e implementação de novos processos de recursos humanos; integração e implementação de culturas organizacionais; comunicação de mudanças e monitoramento do clima organizacional.

Esse mapeamento faz parte das transformações no mundo do trabalho e se alinha ao que foi salientado por Ulrich (1998) sobre os desafios trazidos para as organizações, que exigem que a área de recursos humanos assuma papel fundamental não apenas na definição e execução de ações estratégicas 
de atração, mas também na retenção e no desenvolvimento desses profissionais. O autor ainda chamou a atenção para o que considera sobre as organizações bem-sucedidas: são aquelas que conseguem atrair, reter, desenvolver e compensar profissionais responsáveis tanto por clientes, quanto pelo gerenciamento de crescentes oportunidades tecnológicas. Essa consideração justifica os entrevistados que atribuíram maior peso à retenção de pessoas antigas, consideradas pessoas-chave para o negócio das petroquímicas.

Para os pesquisadores Fleury \& Fleury (2004); Barbosa, Ferraz \& Ávila (2004) a área de recursos humanos deve assumir um papel importante no desenvolvimento da estratégia da organização, à medida que cuida com mais propriedade de atrair, manter e desenvolver as competências necessárias à realização dos objetivos organizacionais. Para os que apontaram o desafio de atrair e reter pessoas da Geração Y foi adicionalmente acrescentada a dificuldade de se estabelecer vínculos com essas pessoas. Esse é outro aspecto a ser considerado no esforço organizacional de atrair, desenvolver e reter pessoas: o da capitalização das competências individuais que agregam valor aos grupos e à organização. No desafio visto pelos entrevistados, na Geração Y, podem estar contidas competências a serem capitalizadas.

A categoria 4 mostra as estratégicas específicas usadas pelas petroquímicas no contexto de mudanças. Os dados da pesquisa mostraram que as organizações petroquímicas mais ágeis sobreviveram. As menores ainda sofrem as consequências das mudanças de contexto. Davel \& Vergara (2001); Casado (2002b) apresentaram em comum, a necessidade de comunicar a visão coerente da organização na cultura organizacional, por meio de persuasão e inspiração, em lugar de edição ou coerção, assim como a necessidade de tudo isso ocorrer de modo compatível com os objetivos da organização e com o crescimento de cada integrante. Esses dados ainda evidenciaram diferenças nas percepções de respondentes entre as organizações de menor e maior porte, no que tange à necessidade apresentada por esses autores. A Figura 05 apresenta os dados obtidos na categoria 'estratégias específicas', que também facilitam o objetivo de analisar as consequências das transformações no alinhamento entre as estratégias de gestão de pessoas e as estratégias dessas organizações petroquímicas.

Revista Ibero-Americana de Estratégia - RIAE, São Paulo, v. 11, n. 3, p. 61-96, set./dez. 2012. 
Gestão Estratégica de Pessoas nas Organizações Petroquímicas de Camaçari - Bahia: Seus Reflexos nas Estratégias de Atração, Retenção e Desenvolvimento de Profissionais

Figura 5 - Categoria 4 - estratégias específicas.

\section{CATEGORIA 4- ESTRATÉGIAS ESPECÍFICAS}

\section{Questão norteadora:}

Quais as estratégias específicas adotadas por essas petroquímicas, no curto, no médio e no longo prazo, para a administração de RH na atração e retenção de profissionais talentosos?

A questão norteadora mostrou os seguintes pontos de convergência entre os respondentes:

É enfatizada a divulgação dos princípios e valores para disseminação da cultura das organizações petroquímicas;

É legitimada a estratégia de manutenção de aposentados, quando da dificuldade de reposição de talentos;

Com a redução de postos de trabalho é dada atenção especial à estratégia de reorientação de carreira, com a ajuda para recolocação no mercado;

As ações de capacitação são desenvolvidas em formato de condomínio e parcerias com SENAI e COFIC;

Abriu-se a perspectiva de investimento na qualificação profissional voltada para o lado comportamental, bem como na qualificação da cadeia de fornecedores/nível de tecnologia /sustentabilidade;

Inserção de mulheres na operação, como esforço consciente da estratégia de inclusão com respeito à diversidade;

Valorização das competências.

Entretanto...

Ainda se fala em contratação de pessoas mais velhas, com mais experiência e maior maturidade em relação à Geração Y.

Fonte: Elaborado pelos autores.

Analisando as forças ambientais, especificamente as vinculadas à tarefa e que influenciam a organização e, consequentemente a gestão estratégica de pessoas, como visto na fundamentação teórica desta pesquisa, observa-se a relevância na coleta de informações acerca das políticas e práticas de gestão de pessoas que mantenham a competitividade tanto na atração quanto na retenção de profissionais talentosos. Os dados das entrevistas mostraram as forças ambientais como atenção à competitividade mundial do setor, área administrativa dessas organizações descentralizada para Rio e São Paulo, redução dos níveis hierárquicos e consequente revisão dos quadros. A influência dessas forças gera, como consequência para a gestão de pessoas, as seguintes ações: responsabilidade compartilhada nos níveis mais baixos das organizações; alinhamento aos objetivos organizacionais mais clarificados; busca de talentos em unidades menores incorporadas; observância aos prazos necessários para integração de culturas de times; busca de resultados 
integrados; plano de crescimento visando à retenção dos melhores talentos; aferição do clima organizacional para tratar mudanças.

A categoria 5 fala dos indicadores de contribuição do tradicional departamento de recursos humanos, o questionamento elucidado na literatura contemporânea da gestão de pessoas utilizada na fundamentação teórica desta pesquisa destacou, como pano de fundo, a gestão estratégica de pessoas na promoção do seu alinhamento pessoas à estratégia organizacional e das mudanças organizacionais, como instrumento adequado para responder aos desafios do ambiente organizacional. A Figura 06 apresenta os dados pertencentes à categoria 'indicadores de contribuição'.

Figura 6 - Categoria 5 - indicadores de contribuição.

\section{CATEGORIA 5 - INDICADORES DE CONTRIBUIÇÃO}

\section{Questão norteadora:}

Nessas organizações petroquímicas, quais os indicadores de contribuição do tradicional departamento de RH para promover o alinhamento das pessoas à estratégia organizacional e facilitar mudanças capazes de responder aos desafios do ambiente organizacional?

Com a questão norteadora dessa categoria, os entrevistados reforçaram que:

Há participação ativa e integradora, ainda que o guia funcional se origine nas matrizes;

Há comprometimento com poder e com as decisões compartilhadas;

Foi conquistada a igual participação nos lucros em todos os níveis;

As pessoas-chave já preconizavam a necessidade de alinhamento há algum tempo;

O alinhamento vem ocorrendo pela evolução natural da gestão de pessoas.

Entretanto...

Encontra-se em processo de criação o novo desenho de gestão, em consonância com o novo desenho da petroquímica nacional.

Fonte: Elaborado pelos autores.

Como pode ser encontrado na fundamentação teórica desta pesquisa, compete à gestão de pessoas conceber, nesse espaço organizacional, políticas e práticas que propiciem o desenvolvimento das competências individuais e a obtenção de comportamentos associados a tais competências. Ao terem aproximado os enfoques comportamental, estratégico e de competências na gestão de pessoas, Wright et. al. (2001) sugeriram que, na perspectiva da gestão estratégica de 
Gestão Estratégica de Pessoas nas Organizações Petroquímicas de Camaçari - Bahia: Seus Reflexos nas Estratégias de Atração, Retenção e Desenvolvimento de Profissionais

pessoas, o denominador comum dos três enfoques requer um conjunto específico de competências e comportamentos desejados das pessoas, de modo a assegurar a implementação das estratégias de negócios e o alcance de metas e objetivos organizacionais.

Considerando-se esse denominador comum dos três enfoques, que requer um conjunto específico de competências e comportamentos desejados das pessoas e comparando-o aos dados das entrevistas e das observações, nota-se que o novo desenho de gestão do qual se falou entre os entrevistados, inclui: RH vinculado ao negócio, compreendendo que o foco nas funções não é mais desejável, uma vez que essas funções podem ser terceirizadas; terceirizações de processos funcionais já se encontram em funcionamento, a partir do mapeamento de processos dessas organizações; profissionais de RH têm feito sua parte em ouvir em todos os níveis; aperfeiçoamento de medição de indicadores de RH; resultados e metas individuais são traçadas, em consonância com os objetivos e metas organizacionais; planejamentos de ações de todas as áreas são ajustados com o RH.

A categoria 6 diz respeito aos indicadores de alinhamento entre as estratégias de gestão de pessoas e a estratégia organizacional.O reporte do conhecimento como ativo estratégico reforça a ideia de que a gestão de pessoas deve ser colocada em alinhamento com a estratégia da organização. Estudiosos como Fleury \& Fleury (2004), Dutra (2004), entre outros, também consideraram que a área de RH deve assumir um papel importante no desenvolvimento dessa estratégia, na medida em que cuida, com mais propriedade, de atrair, manter e desenvolver as competências necessárias à realização dos objetivos organizacionais.

O alinhamento da estratégia de gestão de pessoas à estratégia organizacional é enfatizado pelo enfoque estratégico da gestão de pessoas, como visto na fundamentação teórica desta pesquisa. Esse alinhamento é denominado de externo ou integração vertical.

A integração entre as funções que compõem a área de RH, denominada alinhamento interno ou integração horizontal, deve trabalhar em sintonia com a integração vertical para evitar conflitos e facilitar o processo de ajuste às demandas e pressões do ambiente. A Figura 07 traz os dados obtidos na categoria 'indicadores de alinhamento'

Revista Ibero-Americana de Estratégia - RIAE, São Paulo, v. 11, n. 3, p. 61-96, set./dez. 2012. 
Figura 7 - Categoria 6 - indicadores de alinhamento.

\section{CATEGORIA 6- INDICADORES DE ALINHAMENTO}

\section{Questão norteadora:}

Quais os indicadores de que, nesta organização, a gestão estratégica de pessoas (recursos humanos) preconiza que as práticas de gestão de pessoas devem ser parte integrante das estratégias da organização?

No que tange à questão norteadora dessa categoria, surgiram, nas entrevistas, envolvendo o aprendizado das duas últimas décadas do Pólo, duas perspectivas, outrora não imaginadas pelos executivos de parte das organizações petroquímicas:

Há sempre o que aprender na dinâmica das mudanças e das respostas que as organizações precisam, em todos os níveis hierárquicos;

É preciso acreditar nas pessoas e ajudá-las a dar o melhor de si, para elas e para as organizações.

Daí, as ações sistemáticas de desenvolvimento ficam alinhadas às diretrizes organizacionais para:

Adequação das melhores práticas do mercado;

Sensibilidade da área de RH para promover melhoria da política de gestão de pessoas, voltada para os valores: confiança, empregabilidade, estabilidade, gestão ambiental, segurança, saúde e SGI, sistema com o qual o RH se vê tratando de modo especial em todas essas organizações;

Avaliação 360 graus, envolvendo pares /superiores /colegas / subordinados;

Como resposta à questão norteadora, alinhar foi um verbo comumente encontrado nas entrevistas, ao se falar das dificuldades de se unir culturas nos processos de fusões e incorporações, em razão das mudanças de contexto no mercado petroquímico.

Entretanto...

Entre os entrevistados, o ponto comum foi o cuidado fundamental para que o alinhamento seja feito obedecendo aos valores ditos inegociáveis: humildade, respeito às pessoas, confiança, relacionamento ético e transparência.

Fonte: Elaborado pelos autores.

Fica reafirmada, com os registros dessa categoria, a importância dos alinhamentos vertical e horizontal, conforme apregoado pelo enfoque estratégico na gestão de pessoas, fundamentado por Wright \& Snell (2001) e Lacombe (2005). Reenfatiza-se que o conhecimento investigado nesta pesquisa está atrelado ao conceito de gestão estratégica de recursos humanos, na orientação macro. Relembra-se que esse conhecimento preconiza, essencialmente, que as políticas de gestão de pessoas devem integrar as estratégias da organização, além de redestacar a capacidade da área de RH de reconhecer e identificar os impactos do ambiente organizacional externo, da competição e da dinâmica do mercado de trabalho, como uma das principais características do modelo de gestão estratégica de pessoas.

Revista Ibero-Americana de Estratégia - RIAE, São Paulo, v. 11, n. 3, p. 61-96, set./dez. 2012. 
Gestão Estratégica de Pessoas nas Organizações Petroquímicas de Camaçari - Bahia: Seus Reflexos nas Estratégias de Atração, Retenção e Desenvolvimento de Profissionais

Vale ressaltar a síntese das categorias 1, 2, 3, 4, 5 e 6. Ao invocar os pressupostos epistemológicos de conhecimento e a estratégia de pesquisa utilizada na fundamentação teórica deste artigo, relembre-se que, nos espaços contemporâneos, epistemologicamente a gestão de pessoas pode ser definida, pelo menos, de duas formas. A primeira, tomando-se por base uma orientação micro, centrada nas funções: recrutamento, seleção, desenvolvimento, avaliação e remuneração. Nessa orientação exploram-se as práticas de gestão de pessoas e seus impactos sobre os indivíduos.

A segunda, partindo-se de uma orientação macro, cobre as estratégias gerais de gestão de pessoas adotadas pelas organizações; assume escopo mais abrangente e direciona o exame das práticas de gestão de pessoas para o nível organizacional. Assim, faz-se necessário também relembrar que a estratégia de gestão de pessoas descreve a orientação das organizações, no que se refere à gestão do fator humano. Para tanto, proporciona coesão ao conjunto de práticas, por meio das quais essa gestão é desenvolvida. Observe-se que, as seis categorias foram respaldadas pela segunda orientação, aqui reiterada. A Figura 8 contém a síntese do que foi visto nas categorias 1, 2, $3,4,5$ e 6 .

Figura 8 - Síntese das categorias 1, 2, 3, 4, 5 e 6.

\section{SÍNTESE CATEGORIAS 1, 2, 3, 4, 5 E 6}

Considerando-se as seis categorias, as análises das entrevistas mostram que:

As fusões geraram disponibilidade de mão de obra, o que proporcionou a revalorização das competências, nos ajustes realizados entre as organizações petroquímicas;

Nos processos de capacitar e fazer gestão, os mais bem qualificados foram requisitados;

Nos últimos dez anos tem sido retomada a atenção aos aspectos de competitividade, atentando-se à dinâmica do mercado de trabalho;

Houve mudança no nível dos executivos;

No nível operacional não houve mudanças, em razão das especificidades da mão de obra;

A atuação de RH passou a ser ajustada ao negócio das organizações;

O custo Brasil é alto, o que justifica as fusões.

Fonte: Elaborado pelos autores.

Revista Ibero-Americana de Estratégia - RIAE, São Paulo, v. 11, n. 3, p. 61-96, set./dez. 2012. 
Dois aspectos das mudanças ocorridas no mundo do trabalho foram destacadas como especialmente relevantes por Giannantonio \& Hurley (2002): os profissionais de RH enfrentam um conjunto de questões cada vez mais complexo na prática diária de seus trabalhos; nessa nova realidade os papeis que os departamentos de $\mathrm{RH}$ desempenham nas organizações têm mudado de uma função puramente administrativa para outra que inclui se tornar parceiro estratégico preocupado em adicionar valor à organização.

A Figura 4, além de mostrar a realidade das petroquímicas em Camaçari, também ajuda a responder à questão 'Quais as mudanças em gestão de pessoas, realizadas pelas empresas petroquímicas, a partir da trajetória de diversificação no Complexo Industrial de Camaçari?’

Nessa mesma direção, a gestão de recursos humanos começou a ser considerada uma ampla função, abrangendo estratégias, políticas, práticas, metas e objetivos organizacionais e filosofias globais de gestão de pessoas, conforme salientado por Martín-Alcázar, Romero-Fernádez \& Sánchez-Gardey, (2008). Embora os modelos de gestão de RH originalmente fossem praticamente desconectados do pensamento estratégico, a crescente importância dos recursos intangíveis tem destacado a força de trabalho e as questões sociais das organizações como um elemento central da estratégia.

A Figura 5 mostra a contribuição da gestão de recursos humanos das petroquímicas e ajuda a responder à questão 'Quais as estratégias e práticas que as diferentes organizações petroquímicas de Camaçari, diante das transformações ocorridas no pólo, vêm utilizando para atrair, reter e desenvolver seus profissionais?'

Ainda na fundamentação teórica desta pesquisa foi visto que modelos estratégicos recentes têm focado principalmente em determinantes de alinhamento horizontal da competitividade, movendo-se de uma orientação externa para uma orientação interna. Essa mudança tem produzido um deslocamento da perspectiva tradicional de gerenciamento de pessoas, focada em questões burocráticas e administrativas, para uma orientação mais estratégica. A Figura 7 mostra claramente essa mudança além de ajudar a responder à questão 'Como ocorre o alinhamento entre as integrações vertical e horizontal nessas organizações?'

Por fim, a fundamentação teórica desta pesquisa contribui para o entendimento de que, sob a perspectiva da administração estratégica de recursos humanos as pessoas mudam as estratégias que orientam o relacionamento entre elas e a organização, de acordo com Fischer (1998) e Storey (2001). Assim, a gestão de pessoas deixa de ocupar uma posição secundária em relação às decisões organizacionais estratégicas.

Revista Ibero-Americana de Estratégia - RIAE, São Paulo, v. 11, n. 3, p. 61-96, set./dez. 2012. 
Gestão Estratégica de Pessoas nas Organizações Petroquímicas de Camaçari - Bahia: Seus Reflexos nas Estratégias de Atração, Retenção e Desenvolvimento de Profissionais

Entretanto, essa mudança e o consequente alinhamento não ocorrem de forma simples e linear em todas as funções de RH. Pfeffer (1998) já enfatizava a necessidade de se criar condições necessárias para que todas as áreas funcionais identifiquem competências e comportamentos que as pessoas devem ter para a condução desse alinhamento. As Figuras 6, 7 e 8 deixam à mostra as condições em que as petroquímicas investigadas se encontram nesse alinhamento.

Além do que foi mostrado nas Figuras 1, 2, 3, 4, 5 e 6, por todos os entrevistados, destaca-se uma contribuição substantiva, oriunda da entrevista com a CETREL. Tal contribuição consiste na visão do aprendizado extraído de todas as mudanças ocorridas nas duas últimas décadas, não somente atrelado ao alinhamento da gestão de pessoas ao negócio das organizações, como também à consciência ambiental, envolvendo: projeto financiado pela FINEP, pessoas em níveis de Mestrado e Doutorado; regiões como Camaçari / BA; Triunfo / RS; Duque de Caxias/ Rio; São Paulo e Recife. Essa entrevista gerou, ainda, a contribuição para esta pesquisa, acerca da percepção de mudança da cultura centralizada para a descentralizada, nas organizações petroquímicas desse Pólo.

\section{CONSIDERAÇÕES FINAIS}

A investigação, objeto de estudo desta pesquisa, tomou por objetivos primordiais identificar e analisar quais as mudanças realizadas pelas organizações petroquímicas, a partir da trajetória de diversificação no Complexo Industrial de Camaçari e os seus reflexos nas estratégias de atração, retenção e desenvolvimento de profissionais, tanto em consonância com as justificativas, quanto com a questão formulada. Tal investigação foi respondida em cada categoria e reforçada na junção de todas elas.

Ademais, os resultados apontaram que, nessas organizações há espaço para a área de RH reconhecer e identificar, como uma das principais características do modelo de recursos humanos: atentar para as influências do ambiente organizacional externo; acompanhar a competição e a dinâmica do mercado de trabalho nas petroquímicas nacionais; mapear e redesenhar o modelo de gestão de recursos humanos para o modelo de gestão estratégica de pessoas.

Esses resultados, entretanto, mostraram também, que as mudanças em gestão de pessoas realizadas por essas organizações petroquímicas não são, necessariamente, computadas a partir da trajetória de diversificação do Pólo Petroquímico de Camaçari para Complexo Industrial de Camaçari, de acordo com os dados da pesquisa, mas que as fusões são consideradas entre as principais variáveis responsáveis pelas mudanças ocorridas. Não obstante, há o registro de que essa

Revista Ibero-Americana de Estratégia - RIAE, São Paulo, v. 11, n. 3, p. 61-96, set./dez. 2012. 
mudança de contexto foi benéfica para as petroquímicas, ao favorecer a saída dessas organizações da zona de conforto que se encontravam desde a implantação desse Pólo.

Os dados oriundos das observações, no que se refere: ao acolhimento das visitas; às orientações de segurança; ao tipo de relacionamento com a pesquisadora e com os membros das organizações; à distribuição do tempo individual ou coletivo durante as visitas; aos ritos de chegadas e saídas nas visitas; aos filmes e audiovisuais de apresentação das organizações e folhetos e fichas de apresentação dessas organizações, denotam abertura para o desenvolvimento de futuras pesquisas nessas mesmas unidades de análise.

Esta pesquisa apresenta limitações próprias da abordagem qualitativa, entretanto, a impossibilidade de generalização dos resultados não prejudica a sua relevância, mas, notadamente, abre possibilidades para criação de novas agendas de pesquisas. Com essa perspectiva, pesquisas futuras devem buscar investigar outros momentos das petroquímicas, ainda em Camaçari / BA, quiçá com estudos longitudinais.

Em Camaçari / BA, estender a pesquisa para outros grupos organizacionais, tais como: diretores, gerentes e/ou coordenadores de $\mathrm{RH}$, gerentes de outras áreas funcionais, fora das petroquímicas, em indústrias de transformação e/ou empresas de serviços. Suas percepções serão importantes para traçar um panorama mais completo acerca das mudanças realizadas na gestão de pessoas, a partir da trajetória de diversificação no complexo industrial de Camaçari. Especificamente, poderão ser examinados os reflexos dessas mudanças nas estratégias de atração, retenção e desenvolvimento de profissionais dessas outras unidades de análise.

Para fora do âmbito do Estado da Bahia, estender a pesquisa para examinar as perspectivas de diretores, gerentes e/ou coordenadores de $\mathrm{RH}$, com experiência no pólo e em petroquímicas em Triunfo/RS; Duque de Caxias/Rio; São Paulo e Recife. Especificamente, também poderão ser examinados os reflexos dessas mudanças nas estratégias de atração, retenção e desenvolvimento de profissionais dessas outras unidades de análise.

Revista Ibero-Americana de Estratégia - RIAE, São Paulo, v. 11, n. 3, p. 61-96, set./dez. 2012. 
Gestão Estratégica de Pessoas nas Organizações Petroquímicas de Camaçari - Bahia: Seus Reflexos nas Estratégias de Atração, Retenção e Desenvolvimento de Profissionais

\section{REFERÊNCIAS}

Albuquerque, L. G. \& Leite, N. P. (Org.) (2009). Gestão de pessoas: perspectivas estratégicas. São Paulo: Atlas.

Anthony, W. P., Perrewé, P. L., Kacmar, K. M. (1996). Strategic human resource management. Harcourt Brace Publisher \& Company.

Barbosa, A. C. Q., Ferraz, D. M., Ávila, F. B. (2004). Recursos humanos em direção ao futuro? A gestão de competências em organizações de telefonia móvel. In: Anais Enanpad, 38, Curitiba: ANPAD.

Bardin, L. Análise de conteúdo. Lisboa: Edições 70, 2010.

Becker, B. E., Huselid, M. A., Ulrich, D. (2001). Gestão estratégica de pessoas com scorecard: interligando pessoas, estratégia e performance. Rio de Janeiro: Campus.

Casado, T. (2002a). O indivíduo e o grupo: a chave do desenvolvimento. In: Fleury, M.T. L. at al. As pessoas na organização. São Paulo: Editora Gente, 235-246.

Casado, T. A motivação e o trabalho. (2002b). In: Fleury, M.T. L. at al. As pessoas na organização. São Paulo: Editora Gente, 247 - 258.

Chew, J. C. L. (2004). The influence of human resource management practices on the retention of core employees of Australian Organizations: an empirical study. Thesis (Doctor of Philosophy). Murdoch University.

Chizzotti, A. (2008). Pesquisa qualitativa em ciências humanas e sociais. Petropólis: Vozes.

Cofic / Secretaria da Indústria, Comércio e Mineração do Estado da Bahia. (2008). Carta do Pólo Industrial de Camaçari.

Cooper, D. R.; Schindler, P. S. (2003). Métodos de pesquisa em Administração. Porto Alegre: Bookman.

Davel, E., Vergara, S. C. (Org.) (2001). Gestão com pessoas e subjetividade. São Paulo: Editora Atlas.

Dessler, G. (2003). Administração de recursos humanos. São Paulo: Prentice Hall.

Revista Ibero-Americana de Estratégia - RIAE, São Paulo, v. 11, n. 3, p. 61-96, set./dez. 2012. 
Dutra, J. S. (2002). Gestão de pessoas: modelos, processos, tendências e perspectivas. São Paulo: Atlas.

Dutra, J. S. (2004). Competências. São Paulo: Atlas.

Eisenhardt, K. M. (1989). Building theories from case study research.Academy of Management Review, 14(4), 532-550.

Einsenhardt, K. M., Graebner, M. E. (2007). Theory building from cases: opportunities and challenges. Academyof Management Journal. 50 (1), 25-32.

Fischer, A. L. (1998) A construção do modelo competitivo de gestão de pessoas no Brasil: um estudo sobre as empresas consideradas exemplares. Tese de Doutorado em Administração. São Paulo: FEA-USP.

Fleury, M. T., Fleury, A. (2004). Alinhando estratégia e competências. In: Revista de Administração de Organizações, 44(1), 44-57.

Friedman, B. A. (2007). Globalization implications for human resource management roles. Employ Response Rights Journal, v. 19, pp. 157-171.

Giannantonio, C. M., Hurley, A. E. (2002). Executive insights into HR practices and education. Human Resource Management Review, 12, 491-511.

Guest, D. E. (1987). Human resource management and industrial relations. Journal of Management and Industrial Relations, 24(5), 503-521.

Ivancevich, J. \& Matteson, J. (1996). Organizational behavior and management. Bonston: Irwin.

Lacombe, B. M. B., Tonelli, M. J. (2000). O que nos dizem os especialistas e o que nos mostram as práticas das empresas sobre os Modelos de Gestão de Recursos Humanos. Florianópolis: In: Anais do ENANPAD, 24.

Lacombe, B. M. B., Chu, R. A. (Jan./Mar. 2008). Políticas e práticas de gestão de pessoas: as abordagens estratégica e institucional. In: Revista RAE, 48(1), . 25-35. São Paulo: FGV.

Lacombe, B. M. B. (2005). Avaliação e mensuração de resultados em gestão de pessoas e a relação com o desempenho organizacional: um estudo com as maiores empresas brasileiras. Tese de Doutorado em Administração. São Paulo: FEA-USP.

Lado, A. \& Wilson, M. (1994). Human resource systems and sustained competitive advantage: a competency-based perspective. The Academy of Management Review, v. 19, n. 4, pp. 699-728.

Revista Ibero-Americana de Estratégia - RIAE, São Paulo, v. 11, n. 3, p. 61-96, set./dez. 2012. 
Gestão Estratégica de Pessoas nas Organizações Petroquímicas de Camaçari - Bahia: Seus Reflexos nas Estratégias de Atração, Retenção e Desenvolvimento de Profissionais

Lawller III, E. E. (1991). The phenomenon of large-scale organizational change. São Paulo: Makron Books.

Leite, N. P., Albuquerque, L. G. (2009). Gestão estratégica de pessoas: conceito, evolução e visão. In: Albuquerque, L. G., Leite, N. P. Gestão de pessoas: perspectivas estratégicas, pp.3-16. São Paulo: Atlas.

Leite, N. R. P., Albuquerque, L. G. (2009a). Políticas e práticas de gestão de pessoas: peculiaridades de uma estrutura organizacional remota. Revista de Administração da UFSM ReA, 2(2), pp. 370-394, maio/ago. Santa Maria: UFSM.

Leite, N. R. P., Albuquerque, L. G. (2009b). Os desafios de gerir pessoas em uma estrutura organizacional remota. Revista de Gestão - REGE USP, 16(3), pp. 81-96, jul./set. São Paulo: FEA/USP.

Leite, N. R. P., Albuquerque, L. G. ( Jan./Abr. 2010). A estratégia de gestão de pessoas como ferramenta do desenvolvimento organizacional. Revista Ibero-Americana de Estratégia - RIAE, 9(1), p. 31-53. São Paulo: Uninove.

Leite, N. R. P., Albuquerque, L. G., Kniess, C. T. (Out./ Dez.2010). Reflexões sobre comprometimento e gestão de pessoas em estruturas organizacionais inovativas e remotas. $R A I$ Revista de Administração e Inovação, 7(4), 87-112. São Paulo: Uninove.

Leite, N. R. P., Albuquerque, L. G. (Jan./Mar. 2011). Gestão estratégica de pessoas, comprometimento e contrato psicológico: o caso Vale. Revista de Administração. RAUSP, 46(1), 19-31. São Paulo: FEA-USP.

Lengnick-Hall, M. L., Lengnick-Hall, C. A., Andrad, L.S., Drake, B. (2009). Strategic human resource management: the evolution of the field. Human Resource Management Review, 19(2), 64-85.

Lepak, D. P., Shaw, J. D. (2008, Aug.). Strategic HRM in North America: looking to the future. The International Journal of Human Resource Management, 19(8), 1486-1499.

Mabey, C., Skinner, D., Clark, T. (1998). Experiencing human resource management. London: Sage Publications.

MacLagan, P. (May/1980). Competency, models. Training and Development Journal, v. 34, n. 12 , pp. 40-47.

Martín-Alcázar, F., Romero-Fernandez, P. M., Sanchez-Gardey, G. (2008). Human resource mnagement as a field of research. British Journal of Management, 19, 103-119.

Revista Ibero-Americana de Estratégia - RIAE, São Paulo, v. 11, n. 3, p. 61-96, set./dez. 2012. 
Martín-Alcázar, F., Romero-Fernández, P. M., Sanchez-Gardey, G. (2005, May). Strategic human resource management: integrating the universalistic, contingent, configurational and contextual perspectives. The International Journal of Human Resource Management, 16(5), pp. 633-659.

Marras, J. P. (2000). Administração de recursos humanos. São Paulo: Editora Futura.

Mascarenhas, A. O. (2008). Gestão estratégica de pessoas: evolução, teoria e crítica. São Paulo: Cengage Learning.

Moreira, D. A. (2004). Pesquisa em Administração: origens, usos e variantes do método fenomenológico. In: RAI - Revista de Administração e Inovação, 1, 5-19. São Paulo: Uninove.

Pfeffer, J. (1998). The human equation: building profits by putting people first. Boston: Harvard School Press.

Selltiz; Wrightsman \& Cook. (2005). Métodos de pesquisa nas relações sociais. 2 - medidas na pesquisa social. São Paulo: EPU.

Schuler, R. S., Jackson, S. E. (1987). Linking competitions strategies with human resource management practice. Oxford: Academy of Management Executive.

Schuler, R. S. (1992). Strategic human resource management: linking the people with the strategic needs of the business. Organizational Dynamics, pp. 18-32, Summer.

Storey, J. (2001). Human resource management today: an assessesment. In: Storey, J. (Ed). Human resource management: a critical text. London: Thomson Learning.

Tanure, B., Evans, P., Cançado, V. L. (Jul. /Ago./2010). As quatro faces de RH: analisando a performance da gestão de recursos humanos em empresas no Brasil. In: Revista de Administração Contemporânea-RAC, 14(4), art. 2, 594-614. Curitiba: ANPAD.

Ulrich, D. (1997). Measuring human resources: an overview of practice and prescription for results. HumanResource Management, New York: 36, 3.

Ulrich, D. (1998). Os campeões de recursos humanos: inovando para obter os melhores resultados. São Paulo: Futura.

Ulrich, D. (2000). Recursos humanos estratégicos. São Paulo: Futura.

Ulrich, D., Ulrich, W. (2011). Por que trabalhamos: como grandes líderes constroem organizações comprometidas que vencem. Porto Alegre: Bookman.

Revista Ibero-Americana de Estratégia - RIAE, São Paulo, v. 11, n. 3, p. 61-96, set./dez. 2012. 
Gestão Estratégica de Pessoas nas Organizações Petroquímicas de Camaçari - Bahia: Seus Reflexos nas Estratégias de Atração, Retenção e Desenvolvimento de Profissionais

Ulrich, D., Allen, J., Brockbank, W., Younger, J., Nyman, M. (2011). A transformação do RH: construindo os recursos humanos de fora para dentro. Porto Alegre: Bookman.

Wright, P. \& Snell, S. (2001). Toward an integrative view of strategic human resource management. Human Resource Management Review, v.1. n. 3, pp. 203-225.

Wright, P.; Dunford, B. \& Snell, S. (2001). Human resource and the resource based view of the firm. Journal of Management, v. 27, pp. 701-721.

Vergara, S. C. (2005). Métodos de pesquisa em administração. São Paulo: Atlas.

Yeung, A., Berman, B. (1997). Adding value through human resources: reorienting human resource measurement to drive business performance. HumanResource Management, New York: 3(31).

Recebido: 17/05/2012

Aprovado: 08/08/2012

Revista Ibero-Americana de Estratégia - RIAE, São Paulo, v. 11, n. 3, p. 61-96, set./dez. 2012. 